\title{
Challenges Defining a Life Purpose in an Exam-driven Culture: A Case of Vietnam
}

\begin{abstract}
Hoa Pham ${ }^{*}$
${ }^{1}$ Vietnam National University, Hanoi

*Email: hoapham.ulis@gmail.com

ABSTRACT

As British writer and philosopher Thomas Carlyle once said, "The person without a purpose is like a ship without a rudder," many celebrated names in history have long emphasized the importance of having a life purpose. However, results from recent studies have revealed that many young people face the challenge of exploring their life's purpose, which can be consistent with their exam-driven culture. Intrigued by these findings, I carried out this current research to investigate Vietnam's situation, where the lack of a purpose compass and an exam culture have been criticized by the mainstream media but not widely discussed in academia. Using a mixed-method approach with an online survey and semi-structured interviews, the study was carried out with 135 Vietnamese students, who are either senior high schoolers or first-year students in Northern Vietnam. Findings confirmed that these students are left with little time to explore their purpose, and there is a negative correlation between the exam culture and this lack of purpose.
\end{abstract}

Keywords: life purpose, purposeful education, exam culture.

\section{INTRODUCTION}

The topic of promoting a life purpose among young people has been discussed in both educational and developmental literature worldwide in recent decades. Much as studies might vary in terms of scope and focus, they all concur in the significance of having a life purpose for positive youth development. For example, according to Seligman [1] and French \& Joseph [2], the purpose is an essential contributor to authentic happiness and human flourishing. They argue that defining a life purpose can help people feel a greater level of satisfaction in their lives. Seligman [1] even specifically points out three different paths to happiness and refers to defining a clear life purpose as a way to achieve deeper, long-term contentment. This conclusion aligns with findings from other researchers [3-4], who associate purpose with better psychological health. According to these scholars, the higher the participants' purpose scores are, the more likely they are able to navigate hardships and develop resilience, which in turn increases their psychological health.

Important as it is, the purpose is not discovered naturally by everyone but is, instead, contingent on a number of factors. Johnson [5] suggests that such elements as technology, war, religion, and government largely contribute to the young people's understanding of self and development of a life purpose. In his 2014 book Excellent Sheep: The Miseducation of the American Elite and the Way to a Meaningful Life, Deresiewicz also underscores the critical role of college education with professors and peers in the development of students' life purpose.[6] $\mathrm{He}$ emphasizes that although there are possibilities for one to discover his/her own life purpose, the process is much facilitated by college education and that this is the best place where one can find his/her calling in life. Indeed, the society and culture that people are surrounded with, especially the school environment, can influence their discovery of purpose.

Recently, findings from some research, such as one by Boddy [7], have particularly focused on the exam culture as a phenomenon potentially correlating with the development of youth's life purpose. Implications from these findings have raised critical questions about the impact that an exam-driven culture can have on students' discovery of life purpose. However, although this topic has been investigated in other parts of the world, such as the United States or the United Kingdom, it has so far 
remained a gap in the context of Vietnam education. Therefore, I decided to carry out research to extend on this emerging literature. To be more specific, I would like to conduct a study with a larger and more diverse sample from Vietnam (Boddy's study involves 24 male high school students in the UK) as an attempt to provide further evidence related to the correlation between an exam-driven culture and youth's ability to discover their life purpose. This hopefully would offer new and localized insights into the issue.

I came up with a hypothesis that the exam culture has a negative effect on Vietnamese students' ability to explore their life purpose. In order to test this hypothesis, I worked with a group of 135 students, including both high school students and university students, to investigate the pressures imposed by the high-stake exams they have to deal with and the correlation between these pressures and their capacity to define their life purpose.

\section{LITERATURE REVIEW}

\subsection{Life purpose}

Although most people, both adults, and adolescents, might have a general understanding of what a life purpose is, a number of different definitions have been circulating the literature. Some early studies [1-8-9] propose a broad definition, under which purpose is believed to involve both internally-directed and externally directed sources of the meaning of life.

A more novel approach to the definition of life purpose suggests, "Purpose is a stable and generalized intention to accomplish something that is at once meaningful to the self and of consequence to the world beyond the self' [10]. This definition includes three important components. First, according to this definition, a purpose must represent a clear intention and ultimate stable aim that an individual wants to achieve. Second, a purpose must be meaningful to the individual himself/herself. According to Bronk et al. [11], this self-meaning emphasizes the voluntary nature of the purpose: the individual should voluntarily pursue the purpose and be the driving force behind it instead of merely being motivated by outside factors as parents or peers. Third and most importantly, a purpose should be meaningful to others' well-being and go beyond the benefits of the individual. In other words, a life purpose under this definition underscores the intention to act towards a larger cause, serve a world beyond the self, and make a meaningful contribution to the well-being of other people. Bronk et al. [11] highlight this final component as the central point of the definition as it helps distinguish the definition from earlier approaches as well as other concepts such as meaning. In short, under this novel definition, purpose exists "at the intersection of intention, engagement and contribution" [7]

In this paper, I would like to adopt the definition from Damon et al. [10] due to its ability to clearly define specific components of purpose and its emphasis on the intention to do something larger than oneself. The purpose is a clear and specific goal that one sets to benefit himself/herself and the aim to serve the larger world into which one is embedded.

\subsection{Exam Culture}

In his recent book named Excellent Sheep: The Miseducation of the American Elite and the Way to a Meaningful Life, Deresiewicz [6] portrays an educational system that places a strong emphasis on high-stakes exam testing and a rat race to elite colleges. In that system, students are so consumed by "the clubs, bands, projects, teams, APs, SATs, evenings, weekends, summers, coaches, tutors, 'leadership', 'service"' required to get admitted to top colleges that they are left with little time to explore their life purpose (p. 11). The researcher also expresses his concern that students in the USA are reported to have almost no time and no tools to discover their ultimatums and what they want out of life. [6]

In the same light, another researcher [12] also laments the school system that overemphasizes or even places above all else the importance of high-stakes testing. This concern is shared by other studies, such as one research [13], which finds that $80 \%$ of the teachers' participants stated that the British assessment system 'hinders the development of the whole child'. According to this research, the current exam system in the UK is believed to "hold back the development of a child's moral character" and become so pervasive in schools that it excludes other educational functions. (p.5) More seriously, an increasing number of students in England and Hongkong who have engaged in self-harming behaviors such as suicidal due to the pressures imposed by the exam culture has also been reported. [14]

In this paper, the phrase "exam culture" is used to describe a system similar to those criticized by the aforementioned authors in the United States, United Kingdom, and Hongkong. To be more precise, it refers to a system where students are placed under heavy pressures of exams so frequently that their lives and beliefs are overwhelmed by their performances in tests. In other words, the educational process has become excessively connected with exam preparation to the extent that the two become indistinguishable. [7]

Such an exam culture seems to also exist in Vietnam. According to a report, "the Vietnamese education system is exam-oriented and theoretical." [15] In Vietnam, students' entrance into high levels of education such as high school or university education is decided by their performance in one single test. Admission to public universities and colleges, in particular, is highly competitive and is often considered a great achievement, which also means overwhelming importance is attached to high-stakes exams. Exam periods in Vietnam are even dubbed "suicide season", due to the growing numbers of suicidal cases committed by students upon the announcement of university entrance results every summer. [16] The mainstream media and some studies 
such as one conducted in 2020 [17] even call the phenomenon happening in Vietnam education a degreemindset. Thus, it can be safe to say that Vietnam is a typical example of an exam culture where the pressures to pass exams have overwhelmingly crowded out other educational process aspects.

\subsection{Exam Culture and Life Purpose}

According to Boddy [7], students who have to deal with more pressure to perform well in exams are less likely to have sufficient time to explore their life purpose. His research carried out with 24 male students in the UK reveals that there is a negative correlation between the level of stress experienced by the students and the extent to which they have a sense of purpose. This is because students are so consumed by the test preparations that they have little time to discover their purpose. However, Boddy remains cautious about providing a conclusion about the causal relationship between the two. [7]

Some other scholars put forward another insight about the relationship between life purpose and exam culture: the stress that students feel actually does not stem from the exam culture, but rather their inability to define their life purpose, and therefore a better sense of purpose in life can help reduce the once supposedly exam-induced stress. For example, one scholar asserts that students' unhappiness tends to disappear when they can successfully determine what is meaningful in their life. The stress that they often have to cope with is actually not from the pressures to take exams, but rather from the lack of life purpose. [18]

However, the literature on the relationship between the exam culture and students' ability to explore their life purpose seems to be lacking. Most search results related to the issue of students' life purpose and the testing system come from the mainstream press.

\section{METHODS}

\subsection{Samples}

As my goal in this research is to see if the situation described in Boddy's study about UK students also happens in Vietnam, I start out with a hypothesis that there is also a negative correlation between the exam culture and students' ability to explore their life purpose as portrayed in his study. I followed an almost similar approach that Boddy took in his research and made some adjustments to the size of the samples, the diversity of the samples, and the research instruments with the expectation that the findings can offer new and localized insights. [7]

To be more specific, in this study, I begin by examining the pressures that students feel imposed on them by the Vietnamese education system. After that, I investigate the impact of these pressures on students' exploration of their own life purpose.
In order to do so, I worked with a group of 135 students including both high schoolers and first-year students from three different areas in Northern Vietnam: Hanoi, Hai Phong, and Thai Nguyen. Despite the different locations, all samples are learning at urban schools and universities. Their real origins can, in reality, be more diverse as the group of university students also include those from rural areas who move to Hanoi to pursue their study. These students range from 17 to 19 years old, with 102 belonging to the first group of high schoolers and 33 coming from the second group of university students. This sampling group consists of both boys and girls, which is a striking difference from the sample included in Boddy's study, which only involves 24 male high school students. [7]

The reasons behind this choice of samples are twofold. First, these students are either preparing for the national university entrance exam or recently passing it and getting ready for their first tests at the university, meaning they might experience more obvious levels of exam-induced stress than others. Second, these students are randomly chosen on a mere basis of convenience as I could access them more easily thanks to my personal connection with their schools.

\subsection{Approach, Instruments, and Procedure}

Data collection was done through a mix-method approach with an online survey delivered to 135 students and one-on-one semi-structured interviews conducted with 7 participants. To be more specific, the data collection process can be broken down into the following phases.

Phase 1: I created an online survey using a Google form. The reason behind this choice instead of a Qualtric tool is that Google form is friendly to most students in Vietnam. As many high schoolers, especially those who do not reside in big cities, might not be familiar with using technology, it is really important to deliver the survey on a platform they can easily handle. Google form is often made use of in many activities that students enjoy, such as Facebook confessions.

Due to the time constraints, I could not travel to the schools to meet students in person, yet the online survey might create a better sense of confidentiality and security for the participants.

The survey was adapted from a questionnaire used in Boddy's project in 2015. The whole survey is divided into four major sections: study goals, extracurricular activities, exam culture in Vietnam, and life purpose. To facilitate participants' understanding and to avoid unnecessary, inaccurate information due to language barriers, the survey is translated into Vietnamese. Some questions are also adjusted to suit a new sampling population: university students.

Phase 2: I then piloted the survey with two students in my own class at the university to get their feedback on their experience of filling in the questionnaire. These 
students pointed out some typos and asked me to include clearer instruction about the video question, including reminders about the video subtitles.

Phase 3: In phase three of the data collection process, I contacted some of my colleagues who are currently teaching high school students and one colleague teaching at a university in Hanoi. These colleagues offered me help in contacting their students. It was clear to them that participation is voluntary; they have the complete freedom to refuse to participate. However, to encourage their participation, I stressed that their information would be kept completely confidential, and they would have a chance to get free study materials as appreciation for their participation.

Phase 4: After the survey was collected, I contacted 7 students to do interviews through Zoom. These 7 students were chosen from those who agreed to leave their personal information and provided more detailed answers to open questions in the questionnaire than others. The interviews were done online because it was not easily possible for me to travel to Hai Phong and Thai Nguyen, and upon being given two choices of either online or offline interviews, the participants opted for the former for their convenience. The interviews were recorded, and relevant parts were transcribed.

\section{FINDINGS AND DISCUSSION}

\subsection{Levels and sources of pressures}

In the first part of the survey, the high school students were asked about the goals they set for themselves in the upcoming university entrance exam, while the freshmen were required to provide information about their goals in the first academic year at college. The next two questions inquired about students' evaluation of their possibility to achieve their goals and the reasons why they set such targets.

In response to the first question, most high school students chose the first option (getting 7-10 in the university entrance exam) as their goal. To be more precise, around $80 \%$ of the high school students participating in the survey believed that they would want to get at least a 7 in each test for the university entrance. Only three out of 102 students indicated that they set no goals, and only another three would set a lower target of getting at least a five in the exam. 20 students added other options that reflected their own target, including getting at least 8-9 in each test, getting at least 8.5 on average, getting a high place in the national contest for gifted students in order to secure a place at college, getting admitted to a specific university, getting IELTS 8.0, or studying abroad.

Regarding the students' perceptions of their own goals, most of these students believe that the targets they set for themselves would pose some levels of challenge. 73 out of 102 students considered their goals somewhat difficult, difficult, very difficult, or almost impossible to achieve. Among the remaining 29 students, 22 students believed that their targets would be neither too hard nor too easy.

Answers of the first-year students reflected somewhat a similar tendency with most students setting a high target of getting 3.3 or above (In Vietnam, 3.3 GPA can guarantee one will get a distinction degree). 4 students said that they would aspire to be in the top $10 \%$ of their class or department. Only 4 out of 33 students chose "passing all subjects is enough" as their answers. It is interesting that 8 students added their own options; however, these options are also related to high academic achievements such as "getting a high score", "getting a high GPA", or "getting a high IELTS score". Upon being asked to evaluate their goals, only 8 students believed these goals would be "easy" or "neither easy nor difficult"; the remaining students considered their goals to be difficult at varying degrees.

From these findings, it could be conclusive that the majority of students, including both high schoolers and freshmen, tended to aspire to very high academic achievements and feel concerned about the possibility of reaching their goals.

Moving on to the next question about the reason behind students' goals, "I want to get into a top university" was rated as the most important motivation for high school students while "I want to get a good job" was deemed the most significant reason by the freshmen group. Both groups of students voted "It's important for me to achieve these targets" as their second most important reason for setting their goals. Each of the other options got votes from students as well, indicating that other motivations also exist.

As Vietnamese universities' admission process does not involve students' records of extracurricular activities, I decided to cut this part off the survey. The next set of questions focuses on the impact of the exam culture and educational system in Vietnam on students. In order to facilitate students in completing the survey, I asked them to watch the trailer of a documentary named "Race to Nowhere". This documentary features heartbreaking stories about students who have been seriously suffering from the relentless pressure to achieve in the USA. It highlights some dire consequences of an exam culture and the rat race it creates such as cheating, stress-related illness, burnout, and disengagement. After watching the trailer, participants were asked to express their agreement/ disagreement on a set of statements related to topics raised in the trailer.

Responses to questions in this section display both similarities and differences with findings in other studies about the UK and the US situation. On the one hand, the Vietnamese students participating in this study also expressed their criticism of Vietnam's exam culture. 124 out of 135 students strongly agreed or agreed that the situation portrayed in "Race to Nowhere" could also be experienced in Vietnam; of the remaining participants, 8 did not provide a clear opinion, and only 3 disagreed with 
the statement. A similarly concerning picture could also be seen from the participants' responses to the next statements: an overwhelming proportion of students agreed at varying degrees that they could relate to the students in the trailer as well as feel pressurized or even depressed due to the system in Vietnam.

In the semi-structured interview that followed up the survey, a girl in Hai Phong confessed her burn-out and stress induced by the system:

And about the testing and assessment system in our country, I always feel overloaded trying to deal with different exams and get good marks to be respected by other people. This feeling reached its peak during the entrance exam to my high school. I really had to cope with great pressures about everything. I didn't take part in any extracurricular activities; I just locked myself in my room and learned the whole day.

On the other hand, a striking difference from findings in the literature is that there is a noticeable proportion of students who believed that the exam culture could be beneficial to them in some ways. In the interview with two students, they revealed an opinion that although they admitted the exam-induced stress, they felt that this stress was helpful to them as it promoted their resilience. A participant claimed "diamonds are made under pressure, so are we", revealing his appreciation for the pressures created by the testing system. For him, these pressures provided him with essential motivations to reach his targets.

In conclusion, findings concerning students' goals, sources of motivation, and perceptions of the exam culture in Vietnam seem to lend credence to previous studies researching the situation in other countries. To be more specific, students joining this research also set very ambitious academic goals that they believed were difficult to reach. Their motivation to set such goals mainly came from the expectation to be admitted to a topnotch university or land a good job though other sources of motivation also existed. With regard to the students' opinion on the educational system in Vietnam, the majority of students revealed that they experience a somewhat similar exam culture to that in the USA and that they suffer from stress and burnouts due to this system although there is a noticeable number of students who defended the exam culture.

\subsection{Purpose and correlation between purpose and exam culture}

In the final section of the survey, students were asked to provide information about their life purposes. They were first introduced to the definition and examples of purpose used in this study. I included a simplified version of the definition by Damon et al. [10] and reproduced some examples given by Boddy [7] in this part.

Students' responses to the first question about whether they had a life purpose reflected a slightly different picture painted by Boddy's findings. 82 out of 135 students said that they might have a life purpose but they were not so sure about it; 44 students believed they had identified their life purpose while the 9 others chose "no, I don't know what my life purpose is" in response to the question. At first glance, this seems a more positive situation than what happened among Boddy's samples who overwhelmingly were not sure about their life purpose. However, as those who chose "yes" or "maybe" to the first question continued with the next question where they were required to specify their purpose, results seemed to align with the literature. A majority of answers centered around "becoming a rich person" or "enjoying the money I earn" with few students providing a specific life purpose that aligns with the given definition and examples. Therefore, it could be safer to treat the first question's responses with caution, given they were selfreported by students who were just exposed to the definition very briefly. Students' answers further bolstered this during the interviews. For example, despite claiming that she had identified her life purpose, a participant included "following my dream" as her purpose. When asked further about what the dream exactly was, she said she would need more time to figure it out.

Findings from the next question items could illuminate the correlation between students' ability to find a life purpose and the exam culture. Nearly all participants indicated that they would like to explore their life purpose and that having a life purpose would help them sail through their hardships more easily. However, they also revealed that at present, they would like to focus more on short-term goals such as getting good grades at school or improving their chance to get into a good college. Indeed, 104 students agreed at varying degrees with the statement that "the main task at this stage of my life is to make sure I get the best grades or get into a top university; I will try to explore my life purpose later"; most of the other 31 students expressed a neutral idea towards this. In an interview with a student in Hanoi, she explained that "kids like me always change; I think it is more practical to just focus on my study and try to secure a place at a top university first. I think I have my whole life ahead to explore what I really want to do with my life. If I just focus too much on a goal right now, I am afraid I might change my mind later and regret it."

This finding aligns with students' reaction to the next statement, "I have no time or headspace to look into this right now". Students who took part in the interviews also reiterated this opinion, saying that they were so consumed by the amount of class work, homework, and exams that they would not contemplate "big things" in their life. A student added that whenever he had free time, all he would want to do would be to lounge around to unwind or play games; his study was already too stressful, and did not want to spend more time thinking. However, it was interesting that the interviewed students did reveal some occasions when they were encouraged to explore and follow their life purpose by brief sharings by some of 
their teachers during class time or informal chats with their teachers and senior students.

What could be seen from these results is the consistency with the literature. Although there are certain differences in the way the educational system works here in Vietnam from how it works in other countries like the USA or the UK, Vietnamese students who took part in this study also reflected a similar picture. They also have the motivation to explore what their life purpose is, but might be hindered from doing so by the amount of time and energy required of them to thrive academically at school and in high stakes exams. This, therefore, has lent credence to my hypothesis at the beginning of this research: there is a negative correlation between the exam culture in Vietnam and students' ability to discover their life purpose.

\section{LIMITATIONS}

One major problem with the current study is the size of the sample, especially the number of students who took part in in-depth interviews. A bigger and more diverse sample that includes students from the rural areas and from less well-reputed schools might help paint a more accurate picture of the issue. Furthermore, more energy and efforts invested in conducting more insightful and extended interviews would help shed light on students' real reflections of life purpose.

Furthermore, I would like to acknowledge that although this study expanded its scope by involving both high school students and first-year students, I could not create distinctive sets of questions that tailor to their differences. Therefore, it would be useful for future research to work more specifically on each group's typicalities.

Another problem that I wish to overcome in future research is an improved translation of the term "purpose" in Vietnamese. In my questionnaire and interviews, I referred to "purpose" as "mục đích sống" in Vietnamese and provided quite a detailed definition as well as specific examples. However, as the results turned out, many students did not particularly pay attention to a very important component of the definition, which is to do something larger than themselves. One possible candidate equivalent in Vietnamese might be "lý tưởng sống" or "hoài bão".

\section{CONCLUSION}

Through an online survey delivered to 135 students and semi-structured interviews conducted with 7 participants, the study confirms the amount of stress felt by the sampling population about the exam culture in Vietnam and the negative correlation between this culture and the students' failure to identify their life purpose. This result aligns with findings from the literature about the situations in other countries such as the United States and the United Kingdom although the its findings also highlight some perceptions held by participants that the exam culture helps nurture their overall resilience. This slight divergence, therefore, calls for further studies in culture-driven factors that affect students' perceptions of life purpose.

\section{REFERENCES}

[1] M.E.P. Seligman, M.E.P. Authentic happiness. New York:Free Press, 2002.

[2] S. French \& S. Joseph. Religiosity and its association with happiness, purpose in life, and self-actualisation. Mental Health, Religion \& Culture, 1999, Volume 2(2), 117-120.

[3] D. L. Debats. Measurement of personal meaning: The psychometric properties of the life regard index. In P.T.P. Wong \& P.S. Fry, editors. The human quest for meaning: A handbook of psychological research and clinical applications. Lawrence Erlbaum Associates, Inc, Mahwah (NJ), 2002, pp. 237-259.

[4] V. Frankl. Man's search for meaning: An introduction to logotherapy. Boston: Beacon, 1959.

[5] D. Johnson. Finding Wholeness: Students' Search for Meaning and Purpose in College, Journal of College and Character, 2006, Volume 7(1) , DOI: 10.2202/19401639.1503.

[6] W. Deresiewicz. Excellent sheep: The miseducation of the American elite and the way to a meaningful life. New York, New York: Free Press, 2014.

[7] J. Boddy. Finding purpose in an exam culture: challenges and possibilities for good work. Good Work Project Report Series, 2015, 94.

[8] E. H. Erikson. Childhood and society. New York: W.W. Norton \& Company, 1950.

[9] C.D. Ryff \& C. L. M. Keyes. The structure of psychological well-being revisited. Journal of Personality and Social Psychology, 1995, Volume 69(4), pp 719-727.

[10] W. Damon. The path to purpose: Helping our children find their calling in life. New York, NY: Simon \& Schuster, 2008.

[11] K. C. Bronk, P. L. Hill, D. K. Lapsley, T.L. Talib \& H. Finch. Purpose, hope, and life satisfaction in three age groups. The Journal of Positive Psychology, 2006, Volume 4(6), DOI 500-510 doi:10.1080/17439760903271439

[12] W. Damon, W. The path to purpose: Helping our children find their calling in life. New York, NY: Simon \& Schuster, 2008.

[13] J. Arthur et al. Character Education in UK Schools. The Jubilee Centre for Character and Virtues, 2015.

[14] A. Sharp. Exam culture and suicidal behaviour among young people: Evidence from Hong Kong and England. Education and Health, 2013, Volume 31(1), pp 7-11.

[15] EU-Vietnam Business Network. Education in Vietnam - an annual report, 2015.

[16] S. Trines. Education in Vietnam. [Internet], 2017, Retrieved from:

https://wenr.wes.org/2017/11/education-in-vietnam

[17] T. T. H. Le et al. Factors affecting academic performance of first year university students: a case of a Vietnamese University. International Journal of Education and Practice, 2020, Volume 8(2), pp 221-232. [18] R. Weissbourd. The overpressured student. Educational Leadership, 2011, Volume (8), pp 22-27. 